\title{
EDUCAÇÃO INTEGRAL E GOVERNANÇA NO CONTEXTO DO “NEOLIBERALISMO ROLL-OUT"
}

\author{
INTEGRAL EDUCATION AND GOVERNANCE IN THE CONTEXT OF \\ "ROLL-OUT NEOLIBERALISM"
}

Francisca Pereira Salvino

Resumo: Neste artigo dá-se atenção ao currículo de educação integral no contexto delineado, a partir dos estudos de Stephen Ball, como neoliberalismo roll-out, o qual tem como característica principal a governança em redes, reconfigurando a gestão público-privada para além dos limites do Estado-nação. Nesse contexto, a oferta de educação integral decorre, principalmente, de parcerias público-privadas alavancando sobremaneira o terceiro setor no Brasil, particularmente a partir de 2006 e do movimento Compromisso Todos pela Educação. Toma-se como referência empírica os seguintes programas: i) Mais Educação (PME), sustentado com recursos públicos, trabalho voluntário (licenciandos e quaisquer pessoas da comunidade) e filantropia empresarial; ii) programa Escola Cidadã Integral (Paraíba), cuja gestão é assessorada pelo Instituto Corresponsabilidade pela Educação (ICE), pautada na Tecnologia de Gestão de Pessoas (TGP); no protagonismo estudantil; no planejamento estratégico; e na avaliação rígida. Na Paraíba os programas são recentes e os resultados não mensuráveis. Em Pernambuco, onde o ICE atua desde 2004 o índice de Desenvolvimento da Educação (IDEB) elevou-se da $22^{\mathrm{a}}$ posição para a $1^{\mathrm{a}}$ em 2017 . As principais críticas são de estarem pautadas pela lógica de funcionamento do mercado, forte controle/regulação dos profissionais, dos processos e dos estudantes e de não politização dos sujeitos. Todavia, as escolas e seus sujeitos não são meros reprodutores, per si, do que a elite empresarial e política determina que eles sejam, mas microespaços e sujeitos que ressignificam/repolitizam os currículos, tornando os efeitos e resultados pouco previsíveis.

Palavras-chave: Educação integral. Governança. Neoliberalismo.
Abstract: In this article, attention is given to the integral education curriculum in the context outlined, from the studies of Stephen Ball, such as roll-out neoliberalism, which has as main characteristic the governance in networks, reconfiguring public-private management beyond the limits of the nation-state. In this context, the offer of integral education stems mainly from public-private partnerships, greatly leveraging the third sector in Brazil, particularly since 2006 and the movement Compromisso Todos pela Educação (Commitment All for Education). The following programs are taken as an empirical reference: i) Mais Educação (More Education), supported by public resources, voluntary work (graduates and any community) and business philanthropy; ii) Integral Citizen School program (Paraíba), whose management is advised by the Institute Co-responsibility for Education (ICE), based on the Technology of People Management; in the student protagonism; in strategic planning; and rigid evaluation. In Paraíba the programs are recent and the results are not measurable. In Pernambuco, where ICE has been working since 2004, Índice de Desenvolvimento da Educação - IDEB (the Education Development Index) has risen from 22nd to the 1st in 2017. The main criticism is that they are based on the logic of market functioning, non-politicization of the subjects and strong control / regulation of professionals, processes and students. However, schools and their subjects are not mere reproducers, per si, than the business and political elite determines that they are, but micro-spaces and subjects that resignify/repolize the curricula, making the effects and results unpredictable.

Key words: Integral Education. Governance. Neoliberalism.

\footnotetext{
${ }^{1}$ Doutora em Educação pelo Programa de Pós-Graduação em Educacão (PROPED), da Universidade do Estado do Rio de Janeiro (UERJ) e Professora do Departamento de Educação, da Universidade Estadual da Paraíba (UEPB). E-mail:fpsalvino2@hotmail.com.Orcid: https://orcid.org/0000-0002-8149-019X.
} 


\section{INTRODUÇÃO}

Neste artigo dá-se atenção aos sentidos de educação integral circulantes no contexto da atual fase de desenvolvimento do capitalismo a que se convencionou nominar por globalização neoliberal, especialmente no tocante à política educacional brasileira, entendida não apenas como macropolítica (conjunto de medidas governamentais ou ações do Estado), mas também como micropolítica, voltandose às práticas discursivas próprias dos ambientes escolares, onde as políticas são ressignificadas e implementadas (BALL, 2006).

Situando o objeto de estudo, considero como cenário contemporâneo a fase de desenvolvimento do capitalismo que se delineia nas primeiras décadas do século XXI e como uma primeira possibilidade de pensar o currículo a ideia de Pinar (apud LOPES e MACEDO, 2011) de currículo como processo, como conversa complicada de cada indivíduo com o mundo e consigo próprio, uma ação, um sentido particular e uma esperança pública. Nesse cenário procuro enfatizar o capitalismo não como um modelo único, concreto, homogêneo, mas como paradigma político, econômico e filosófico que se transmuta no tempo/espaço e projeta-se em diferentes modos de conformação, em diferentes projetos societários, que necessitam ser situados histórica e culturalmente. Trata-se, portanto, de modos de produção de bens materiais e simbólicos com incríveis capacidades para se recriarem, reestruturarem-se, recontextualizarem-se a partir de suas próprias crises e contradições e de outros, ainda que mantendo a mesma base político-econômica e filosófica: o liberalismo. Refiro-me ao filosófico porque nele encontram-se princípios éticos, morais, estéticos acerca dos modos de ser, pensar e estar no mundo. Modos de identidade e de diferenciação.

Consideramos que o Brasil encontra-se na terceira revolução industrial, que tem sido denominada de sociedade do conhecimento, provavelmente em transição para um novo paradigma ainda não nomeado/consolidado. As marcas dessa fase para pensar o currículo de educação integral são o avanço incomensurável das Tecnologias de Informação ( $\mathrm{TI})$ e de transportes, que redimensiona a expansão dos mercados em escala local/global; o acesso às informações tanto para o bem como para o mal; as redes sociais que mesclam o real/virtual, que de maneira estonteante tanto aproxima como distancia as pessoas; o esgarçamento dos limites entre Estado, mercado e sociedade civil; o crescimento do terceiro setor por meio de parceria, terceirização, privatização; a banalização da violência e da vida; e a desesperança.

Nesse cenário, estudantes e profissionais de Instituições de Ensino Superior (IES) e de educação básica, nas esferas pública e privada são desafiados a pensar e projetar (planear, realizar, avaliar) currículos de educação integral que dependem cada vez mais de redes políticas complexas, rápidas, dinâmicas, eficientes com consequências (benéficas e maléficas) para a vida pública e privada pouco conhecidas.

\section{O NEOLIBERALISMO ROLL-OUT E O MOVIMENTO “COMPROMISSO TODOS PELA EDUCAÇÃO”}

Neoliberalismo é um desses termos cujo sentido foi banalizado, por osso, é necessário apropriarse dele com prudência, entendendo-o não apenas por se tratar de um daqueles termos que é utilizado de forma tão ampla e vaga que corre o risco de tornar-se sem sentido como assevera Ball (2014), mas por se tratar de um significante vazio (LACLAU e MOUFF, 2015), em torno do qual diferentes sujeitos, individual e coletivamente, empreendem esforços para dar-lhe significado e hegemonizá-lo. Há, portanto, deslocamento, excesso, transbordamento de significados na órbita do neoliberalismo, bem como disputas acirradas para os tornar hegemônicos. Nessa órbita recorro a Ball (2014, p. 25) para pensar o neoliberalismo não enquanto doutrina econômica concreta ou conjunto definido de projetos políticos, mas enquanto

Conjunto complexo, muitas vezes incoerente, instável, e até mesmo contraditório de práticas que são organizadas em torno de certa imaginação do 'mercado' como base para a 'universalização das relações sociais baseadas no mercado, com a correspondente penetração em quase todos os aspectos de 
nossas vidas, do discurso e/ou práticas de mercantilização, de acumulação de capital e de geração de lucros'.

Ball (2014) reconhece três fases de desenvolvimento do neoliberalismo, a saber: i) "proto" neoliberalismo, referindo-se ao projeto intelectual, moldado por Hayek, Fridmam e outros teóricos econômicos da vertente liberal rastreáveis até Adam Smith e David Ricardo, que fundamentaram a construção discursiva de uma crise política e econômica em torno do Estado do Bem-Estar, bem como as alternativas a ela; ii) neoliberalismo roll-back, referindo-se ao momento de "destruição ativa" e descrédito das instituições keynesiano-assistencialistas e sociais coletivas, que marcam as proposições em torno do Estado do Bem Estar; iii) neoliberalismo roll-out, referindo-se ao momento de construção e consolidação de formas de estado neoliberalizadas, de modos de governança e regulações por meio da introdução de novas instituições, políticas e governamentabilidade.

Numa tentativa de aproximação ao Estado brasileiro pode-se afirmar que a reforma implementada durante o governo de Fernando Henrique Cardoso é característica do movimento neoliberalismo rollback, tendo como especificidade o fato de que o Brasil não havia chegado a implementar um Estado de Estar que justificasse redução de investimentos. Pelo contrário, no caso da educação, houve aumento destes, ainda que se adotando políticas focais. Já a política de pactuação, adotada durante o governo Luiz Inácio Lula da Silva o Plano de Aceleração do Crescimento (PAC) e seu Plano de Desenvolvimento da Educação (PDE) são característicos das redes de políticas que intensificam o crescimento do terceiro setor, por meio do movimento Compromisso Todos pela Educação e de parcerias entre instituições públicas e privadas.

Acordos, parcerias, convênios e outras formas de contrato entre instituições estatais e privadas (com ou sem fins lucrativos) são antigas e ocorrem em diferentes sociedades e formas de governo. Todavia, elas se tornaram mais frequentes e decisivas a partir da década de 1990 com os adventos da globalização e do neoliberalismo, potencializados pelo desenvolvimento das tecnologias da informação, da comunicação e dos transportes. Esse contexto, configurando o que se convencionou chamar de "sociedade do conhecimento", consagrou a educação e o currículo como fatores estratégicos para o desenvolvimento econômico e humano, mas também consagrando conflitos e problemáticas, que desafiam a gestão educacional, tanto ao nível das macro políticas, quanto no cotidiano escolar.

Como nos lembra Saviani (2008), a relação conflituosa entre o público e o privado no Brasil remonta à chegada dos portugueses ao país, quando chegaram, em 1549, Tomé de Souza e quatro padres jesuítas, trazendo os "Regimentos" de D. João III para orientar as ações do primeiro governador geral do Brasil. Os "Regimentos" destinavam verbas, ainda que exíguas, para manutenção do ensino a ser ministrado pelos jesuítas. Já nessa política, a opacidade entre público (monarquia portuguesa) e privado (igreja) ficam evidentes. Tanto foi que em 1759, quando o iluminista Marquês de Pombal expulsou os jesuítas do Brasil, nada havia em termos de estrutura física para a educação pública estatal, conforme defendia o Marquês. Na falta desta infraestrutura, as "aulas régias" eram pagas com recursos públicos, porém ministradas, na maioria das vezes, em espaços privados, tais como as residências dos/as professores/as ou outros espaços cedidos por pessoas que, de alguma forma, preocupavam-se com a instrução das crianças brasileiras, já que o problema pouco afetava as elites políticas daquela época.

A falta de estrutura, o descaso das elites políticas e a insuficiência de recursos mantiveram a educação praticamente sem avanços até o início do século XX, quando a industrialização e a urbanização do país, impuseram a necessidade de maiores investimentos e de ações mais efetivas no sentido da construção de uma educação pública estatal, laica e gratuita, que atendesse à população. Essa necessidade motivou, dentre outras ações, o "Manifesto dos Pioneiros da Escola Nova" em 1932. Ainda a partir desse momento, os avanços seguiram lentamente em comparação com outros países, inclusive da América Latina, como Argentina, Chile e Uruguai. Entre avanços e retrocessos, o Brasil chega à década de 1990, acompanhando a terceira revolução industrial, ainda que de forma tardia. Contudo, os indicadores 
sociais e educacionais continuaram a evidenciar o descaso do poder público com o desenvolvimento humano e com a distribuição de renda, para a qual muito contribui os níveis de escolarização.

Dados da Organização for Economic Co-operacion and Desenvolviment (OECD) constata que o maior nível de escolaridade aumenta a probabilidade de ser empregado. Em média, nos países da OECD, a taxa de emprego é de cerca de 85\% para adultos com educação superior (25-64 anos); 75\% para adultos com qualificação secundária ou pós-secundária não superior; e menos de $60 \%$ para adultos que não completaram o ensino superior. Apesar do reconhecido e das evidências, o Brasil continua na contramão da história, especialmente no tocante à qualidade da educação, posto que as últimas três décadas evidenciam avanços significativos quanto ao acesso, à permanência e à distorção idade-série.

Esses avanços são percebidos a partir da década de 1990 e da redemocratização do Brasil, pós Ditadura Militar (1961-1985), inicialmente sob a égide do governo de Fernando Henrique Cardoso (FHC: 1994-2002), quando os esforços ocorreram na tentativa de modernizar o Estado a partir das orientações emanadas do "Consenso de Whashington" $(1988)^{2}$. Por conseguinte, resultou também em reforma na educação, delineada principalmente com a seguinte legislação: Leis $n^{\circ}$ 9.394/1996 que estabelece diretrizes e bases para a educação nacional (LDB); Lei n 9.424/1997, que criou e regulamentou o Fundo de Manutenção e Desenvolvimento do Ensino Fundamental e Valorização do Magistério (FUNDEF), substituído pela Lei n $11.494 / 2007$, que criou e regulamentou o Fundo de Manutenção e Desenvolvimento da Educação Básica e Valorização dos Profissionais da Educação (FUNDEB); Lei nº 10.172/2001, que aprovou o Plano Nacional de Educação (PNE), substituída em 2014 pela Lei $n^{\circ}$ 13.005/2014, que aprovou o PNE em vigor atualmente; Parâmetros Curriculares Nacionais (PCN); diretrizes educacionais para os diferentes níveis, etapas e modalidades educacionais, várias delas organizadas em um documento intitulado Diretrizes Nacionais para a Educação Básica (2013). Esses, dentre outros textos jurídiconormativos, representam em grande medida o esforço de determinados segmentos da sociedade em defesa da escola pública e da garantia de investimentos estatais exclusivamente para a educação pública. Todavia, a própria legislação regulamentou a coexistência dos regimes público e privado de educação, incluindo nesta, as instituições comunitárias, confessionais e filantrópicas (BRASIL, 1996). O agravante é que isto legitima a coexistência de dois sistemas marcadores da desigualdade social que assola o país, uma vez que o sistema público segue atendendo prioritariamente às populações mais desfavorecidas economicamente, e o privado às populações mais favorecidas.

Sobre os efeitos das políticas empreendidas a partir de 1990, Frigotto (2011) avalia haver evidências relevantes do interesse de empresas privadas pela educação como negócio, que se prolongaram e acentuaram na primeira década do século XXI. A exemplo disso, o autor cita dados de Grabowsky (apud FRIGOTTO, 2011) que comprovam essa perspectiva, dos quais destacamos: 1) a compra do Anglo Sistema, do Anglo Vestibulares e do Siga pela Abril Educação, perfazendo um faturamento de 500 milhões de reais em 2010; a diferença na distribuição das matrículas do ensino técnico, no qual $25 \%$ eram em escolas públicas e 75\% em privadas, em 1999; e o Sistema S (SENAI, SESI, SENAC, SEST-SENAT) que mobilizou cerca de 16 bilhões de recursos públicos (recolhidos pelo Estado compulsoriamente e repassados ao Sistema e vendas de serviços ao setor público), sendo esse valor superior ao que a União previu investir com FUNDEB; Bolsa-Família; expansão da rede federal de educação; Brasil Profissionalizado; Projovem e demais programas do campo da educação e qualificação profissional.

O que se constata é que as políticas educacionais empreendidas a partir da década de 1990 têm sido bastante promissoras às parcerias público/privado, resultando em terceirização de determinados serviços; isenções de impostos, mediante oferta de vagas em instituições privadas; financiamento estudantil para compra de vagas em instituições privadas e outras. Para exemplificar, em 2014, dados do INEP confirmavam a crescimento da acesso ao ensino superior, todavia, enquanto as IES públicas contabilizavam $27 \%$ das matrículas, as privadas contabilizavam $73 \%$. Para esse crescimento

\footnotetext{
2 Neste, autoridades de diversas partes do mundo elencaram medidas a serem adotadas por países que se encontravam em crise econômica e política (hiperinflação; desequilíbrio fiscal e monetário; desvantagem na relação importação/exportação; dívida externa e interna; declínio/transição de regimes políticos e outros).
} 
desproporcional muito contribuíram o programa de Financiamento do Ensino Superior (FIES) e Programa Universidade para Todos (PROUNI).

Cresceram também o número de instituições educacionais sem fins lucrativos; ações de organizações não governamentais; convênios em que instituições públicas delegam a gestão ou outros serviços à empresas privadas, tais como, Instituto Airton Senna, Fundação Bradesco, Instituto Camargo Corrêa, Fundação Lemann, Instituto de Corresponsabilidade pela Educação (ICE) e outras.

Essa tendência cresceu e consolidou-se com o movimento "Compromisso todos pela educação" (2006), durante o segundo mandato do governo de Luiz Inácio Lula da Silva, quando o Ministério da Educação (MEC) forjou uma ampla pactuação em defesa da educação, mobilizando diferentes sujeitos sociais (SHIROMA, GARCIA e CAMPOS, 2011). Este movimento é entendido pelas autoras como liderado pela classe empresarial, atinente ao ideário neoliberal em sua configuração revista e adotada a partir da primeira década do século XXI. Principalmente na América Latina, esse movimento manteve e aperfeiçoou um forte apelo à sinergia e à responsabilização dos diversos setores da sociedade em defesa do direito à educação. Analisando as tendências à definição de políticas a partir de contextos de influência globais (internacionais) e como elas impactam as políticas locais, as autoras concluem que o movimento adotou discursos fortes e insistentes, capazes de converter almas pela liturgia da palavra (SHIROMA, GARCIA e CAMPOS, 2011), que seriam discursos recorrentes para legitimar a lógica de mercado na gestão educacional. É esse movimento que, a meu ver, marca a inserção do Brasil no que Ball (2014) denomina de neoliberalismo roll-out. Nessa linha de análise, Ball (2014, p. 87) assevera que

As redes políticas constituem uma nova forma de governança, embora não de uma forma única e coerente, e colocam em jogo, no processo de políticas, novas fontes de autoridade e, de fato, um 'mercado de autoridades'. [...] nacionalmente o setor educacional público está mais congestionado; novas relações e formas de relacionamento estão sendo estabelecidas dentro da política e em relação a ela, isto é, há uma nova mistura dentro da matriz de governança envolvendo 'relações complexas de interdependência recíproca'; as fronteiras entre o Estado, a economia e a sociedade civil estão ficando turvas; há novas vozes nas conversas sobre as políticas e novos canais por meio dos quais os discursos sobre políticas introduzem o pensamento sobre políticas; e as organizações 'operacionalmente autônomas', mas 'estruturalmente acopladas.

Para Ball (2014), a governança em redes tem duas características básicas: i) desestatização mais ou menos radical, sujeitando organizações públicas à concorrência e ou à entrega da prestação de serviços educacionais a instituições privadas; ii) reafirma o papel do Estado, mas numa tendência pós-neoliberal, numa nova modalidade que envolve mudanças de governo de burocracia para redes, de prestador de serviços para contratante. Além disso, essas redes têm suporte nas TI avançadas que possibilitam suas composições em escala que extrapola os limites do Estado-nação. Assim, os entes federados podem contratar e ou estabelecer parcerias diversas com instituições, grupos, redes de diferentes lugares.

Essas instituições se conectam e operam em diversos países nos processos de gestão administrativa e pedagógica das redes educacionais e das escolas; de ensino e aprendizagem; da avaliação e divulgação de informações, intervindo desde o planejamento das políticas. Segundo o documento Education at a glance 2017 (OECD, 2017) $)^{3}$ os governos estão cada vez mais buscando comparações internacionais de oportunidades e resultados para desenvolverem políticas que melhorem as perspectivas sociais e econômicas dos indivíduos, fornecendo incentivos para uma maior eficiência na escola, e ajudar a mobilizar recursos para atender às demandas crescentes.

\footnotetext{
3 Preparado pela equipe da Inovação e Medição da Divisão de Progresso da Diretoria de Educação e Competência da OECD, sob a responsabilidade de Dirk Van Damme e Marie-Hélène Doumet e cooperadores.
} 
O Documento afirma que na maioria dos países da OECD, nos quais prevalece a política de parceirização, no máximo, apenas $5 \%$ dos adultos não atingiram o ensino primário, com algumas exceções notáveis, tais como: Brasil (17\%), Costa Rica (13\%), Índia (46\%), México (14\%) e África do Sul (15\%) (OECD, 2017). Em média, nos países da OECD, $6 \%$ dos adultos foram educados apenas para o nível primário, mas essa porcentagem é muito mais elevada em alguns países, nomeadamente China (25\%), Costa Rica (29\%), Indonésia (43\%), Portugal (30\%), Arábia Saudita (24\%) e Turquia (43\%). Entre os adultos mais jovens (25-34 anos), em média, nos países da OCDE, a proporção destes com ensino médio caiu de $25 \%$ em 2000 para $21 \%$ em 2005, 19\% em 2010 e 16\% em 2016 (OECD, 2017).

Segundo o documento (OECD, 2017), essas avaliações que comparam o desempenho dos países é importante para dar a todos uma oportunidade justa de obter uma educação de qualidade e isto deve ser planejado desde as etapas iniciais, quando a educação integral exerce função primordial para garantir indicadores educacionais mais equânimes e uma melhoraria na mobilidade social. Resultados socioeconômicos são extremamente importantes para remover desigualdades nas oportunidades de educação e promover o crescimento inclusivo através da ampliação de empregos mais qualificados. A forma mais adequada de distribuição de renda é por meio de remuneração do trabalho/emprego e o investimento em formação nas diversas áreas amplia as oportunidades, o que é fundamental numa situação em que os mercados se modificam freneticamente, eliminando vagas de emprego mais do que criando.

\section{EDUCAÇÃO INTEGRAL NO ENSINO FUNDAMENTAL POR MEIO DE TRABALHO VOLUNTÁRIO E FILANTROPIA EMPRESARIAL}

No movimento Compromisso Todos Pela Educação ocorre uma ênfase na oferta de educação integral ou em tempo integral, com a finalidade de atender à meta 6 do PNE/2014. No âmbito do ensino fundamental, chama-nos a atenção o Programa Mais Educação (PME), que a partir de outubro de 2016 foi reformulado e passou a ser denominado de Programa Novo Mais Educação (PNME). A reformulação decorreu da mudança de governo após o impeachement de Dilma Rousseff e a ascensão do seu vicepresidente, Michel Temer. O PME move uma rede de negócios em torno da compra de equipamentos, instrumentos musicais, livros e outros materiais. Porém, o PME estrutura-se não a partir de filantropos empresários, mas de jovens pobres (em sua maioria licenciandos) atraídos para uma prestação de serviço voluntário, pelo qual recebem uma exígua ajuda de custo no valor de $\mathrm{R} \$ 80,00$, por turma, em escolas urbanas e $\mathrm{R} \$ 120,00$ em escolas rurais. Com esse tipo de “mão de obra" voluntária o PME chegou a atender, em 2014, 60 mil escolas em todo o território nacional com oferta de educação integral, correspondente a $42 \%$ do percentual estabelecido pela Meta 6 do PNE de 2014, que é de 40\% (SALVINO e ROCHA, 2015). Ou seja, atende a mais alunos com menos recursos do que gastaria com o sistema regular/parcial de ensino. Contudo, em 2015 o PME enfrentou sérios problemas, tais como sua suspensão em virtude do corte de verbas na educação da ordem de mais de 10 bilhões; evasão e alto absenteísmo; dificuldade para implementação dos macrocampos (campos disciplinares oferecidos no contra turno das aulas regulares).

Em 2015 e 2016 o PME quase foi extinto devido aos cortes de verbas da educação. Em Campina Grande/PB, por exemplo, funcionou em algumas escolas graças a convênio pré-existente com o Instituto Alpargatas, que vem tendo intensa participação nesse município e em outros. O Programa é regulamentado pela Lei $n^{\circ}$ 9.608, de 18 de fevereiro de 1998 , que dispõe sobre prestação de serviços voluntários e outras providências. Ou seja, uma outra modalidade de filantropia, extremamente perversa porque o grande contingente dessas pessoas é de estudantes de cursos de licenciatura, reconhecidamente situados dentre as famílias com os menores níveis de renda entre os estudantes de graduação. Às custas dos mais pobres, o governo oferta maior acesso à educação em tempo integral e como bem menos recursos.

Sobre essa parceria, Medeiros (2013) analisou a implementação do Sistema de Gestão Integrado (SIG) em quatro escolas do citado município, a partir da percepção de gestores/as e professores/as. O SIG é um projeto desenvolvido com a colaboração do Instituto Camargo Corrêa, criado em 2003 como braço social da Empresa Alpargatas, a maior empresa brasileira de calçados e artigos esportivos. Dois projetos 
foram desenvolvidos através do SIG, a saber: Programa Escola Ideal e Educação por meio do esporte. A autora conclui que, apesar de representar a adesão de doze escolas ao ideário neoliberal, os/as participantes da pesquisa avaliam positivamente a parceria.

No ensino fundamental, em Campina Grande/PB das 120 escolas (urbanas e rurais), 119 estão sendo assessoradas pela Fundação Lemann desde 2016, com contrato para atuar por três anos. Em outubro de 2017, representantes da Secretaria de Educação participaram em São Paulo (SP) do $1^{\circ}$ Encontro Nacional Redes que Transformam, do Programa Formar, realizado pela Fundação em parceria com a Elos Educacional e o Mathema (PARAÍBA ONLINE, 2017). O evento reuniu secretários municipais e estaduais de educação, líderes das secretarias, equipes técnicas e pedagógicas, objetivando compartilhar práticas e trocar experiências, participando de painéis temáticos sobre os desafios da gestão, perenidade em políticas públicas e reflexões sobre a Base Nacional Comum Curricular (BNCC).

No dia 9 de março de 2018, a Fundação realizou um encontro nacional especial com vinte e quatro redes municipais ${ }^{4}$ de educação finalistas no processo seletivo para participar do Programa Formar, que é uma parceria pela aprendizagem já colaboradora com mais de 600 mil alunos em todo o Brasil (FUNDAÇÃO LEMANN, 2018). No dia 22 do referido mês, o Google anunciou uma doação de R\$ 15,8 milhões para a Fundação Lemann por meio do seu braço filantrópico Google.org. O valor seria destinado ao financiamento de um projeto liderado pela Associação Nova Escola para formação de professores brasileiros para a sala do futuro. O valor fazia parte de aporte de 50 milhões que a Google havia se comprometido em repassar para instituições filantrópicas (TERRA, 2017). A Fundação de Jorge Lemann, o empresário mais rico do Brasil e também proprietário da AMBEV, tem como diretor executivo Denis Mizne, desde 2011 cofundador da campanha Sou da paz iniciado em 1997. Segundo Mizne (BORGES, 2016), "nunca houve tantos recursos para impacto sociais, se no passado trabalhar com impacto social significava optar por uma vida de abnegações e complicações, hoje o cenário é outro, sendo possível atuar no terceiro setor, em startups, no governo". Uma das suas mais recentes apostas é a Escola que Eleva, que tem como foco o ensino médio em período integral (BORGES, 2016).

Analisando essa e outras parcerias análogas Thiessem e Durli (2016), concluem que o foco de ação destas organizações tem sido o território da gestão curricular das escolas por via de acordos e contratos com redes públicas de ensino, as quais se mostram

cada vez mais permeáveis a esta ocupação negociada. O/a autor/a avaliam que a opção do mercado por ocupar este território deve-se ao fato de o currículo escolar representar o que há de mais objetivo e concreto no aspecto da escolarização na formação humana desde a educação escolar mais geral na Educação Básica até a profissional, ação esta que interessa tanto ao modelo capitalista em geral quanto ao mercado em particular.

\subsection{Educação integral no ensino médio por meio de parceria com o Instituto de Corresponsabilidade pela Educação - ICE}

Compondo as ações do PDE e do Movimento Compromisso todos pela Educação foi lançado o Programa Ensino Médio Inovador (Pro-EMI), instituído pela Portaria $\mathrm{n}^{\circ}$ 971/2009 (BRASIL, 2009), tendo como finalidade a oferta de educação integral em tempo integral, perseguindo uma sofisticada proposta de intersetorialidade. Caracteriza-se como estratégia para promover a reestruturação/inovação dos projetos curriculares do Ensino Médio e a consequente elevação dos indicadores relativos ao acesso, à permanência e à qualidade dessa etapa da Educação Básica. Ancorado na Constituição Federativa do Brasil de 1988, na Lei nº 9.394/1996, Lei de Diretrizes e Bases da Educação Nacional - LDB (BRASIL, 1996); nas Diretrizes Curriculares Nacionais da Educação Básica

\footnotetext{
4 Redes finalistas: São Paulo (Caraguatatuba, Embu das Artes, Idaiatuba, Itatiba, Jundiaí, Mogi das Cruzes e Piracicaba); Pernambuco (Cabo de Santo Agostinho, Paulista e Caruaru); Ceará (Aquiraz); Maranhão (Codó e S. J. do Ribamar); Maceió (Alagoas); Rio de Janeiro (Magé e N. Iguacu); Amazonas (Maués); Rio G. do Sul (Porto Alegre e Pelotas); Piauí (Teresina); Goiás (Valparaízo) e M. Gerais (Vespasiano).
} 
(BRASIL, 2013a) aprovadas através do Parecer $n^{\circ}$ 7, de 7 de abril de 2010 (BRASIL, 2013b), no PNE/2014, o Pro-EMI pretende ampliar a jornada diária de aulas para um mínimo de sete horas e tornar o ensino mais atrativo aos estudantes. O programa pretende oferecer educação integral em nível de Ensino Médio $\left(1^{\circ}\right.$ a $3^{\circ}$ ano) em escolas públicas estaduais, que é a terceira etapa da Educação Básica e, provavelmente, a que tem apresentado os piores indicadores. O Programa é financiado com recursos públicos federais do Fundo Nacional de Desenvolvimento da Educação (FNDE), através do Programa Dinheiro Direto na Escola (PDDE) e também sofreu modificações com a mudança de governo em 2016.

Comparado ao ensino fundamental, o ensino médio apresenta uma série de agravantes, tais como déficit na oferta de vagas e de professores, percentual elevado de abandono e de distorção idade/série como os dados do Quadro 1 revelam

Quadro 1 - Número de habitantes e percentual de distorção idade-série no Ensino Médio em diferentes localidades

\begin{tabular}{|l|c|c|c|c|c|}
\hline \multirow{2}{*}{ LOCALIDADES } & \multirow{2}{*}{ HABITANTES (2016) } & \multicolumn{2}{|c|}{ ESTADUAIS } & \multicolumn{2}{c|}{ PARTICULARES } \\
\cline { 3 - 6 } & & $\mathbf{2 0 1 2}$ & $\mathbf{2 0 1 5}$ & $\mathbf{2 0 1 2}$ & $\mathbf{2 0 1 5}$ \\
\hline Campina Grande - PB & 407.754 & $46 \%$ & $42 \%$ & $07 \%$ & $07 \%$ \\
\hline Olinda - PE & 390.144 & $55 \%$ & $41 \%$ & $08 \%$ & $07 \%$ \\
\hline Mogi das Cruzes - SP & 429321 & $17 \%$ & $13 \%$ & $03 \%$ & $04 \%$ \\
\hline Luziânia - GO & 196.864 & $39 \%$ & $32 \%$ & $07 \%$ & $05 \%$ \\
\hline Brasil & & $35 \%$ & $30 \%$ & $08 \%$ & $07 \%$ \\
\hline
\end{tabular}

Fonte: A autora, a partir de dados disponíveis em http://www.qedu.org.br. e http://www.ibge.gov.br/home/

Comparando os índices de distorção idade-série de quatro municípios de Estados diferentes percebe-se uma situação já conhecida, o fato de que os piores indicadores educacionais encontram-se na Região Nordeste do Brasil. Ao Pro-EMI, portanto, foi atribuída a função de reverter o quadro dramático do ensino médio possibilitando às comunidades escolares redesenharem seus currículos na perspectiva da inovação, da iniciação científica e da integração curricular. Na Paraíba, o Programa teve início em 2009, passando efetivamente a funcionar em 2012 com a adesão de 27 escolas, número que foi ampliado para 48 em 2013 e para 49 em 2014. Em Campina Grande/PB, o Pro-EMI foi adotado em quatro escolas em 2012, nas quais foi substituído a partir de 2016 pelo Programa Escola Cidadã Integral e adotado em outras escolas, conforme o Quadro 2 a seguir.

Quadro 2 - Mudanças na adesão das escolas ao Pro-EMI

\begin{tabular}{|c|l|l|l|l|l|l|l|}
\hline $\mathbf{N}^{\mathbf{0}}$ & \multicolumn{1}{|c|}{ ESCOLAS } & $\mathbf{2 0 1 2}$ & $\mathbf{2 0 1 3}$ & $\mathbf{2 0 1 4}$ & $\mathbf{2 0 1 5}$ & $\mathbf{2 0 1 6}$ & $\mathbf{2 0 1 7}$ \\
\hline 1 & EEEFM Severino Cabral & $\operatorname{Sim}$ & $\operatorname{Sim}$ & $\operatorname{Sim}$ & $\operatorname{Sim}$ & $\operatorname{Sim}$ & Não \\
\hline 2 & EEEFM Isabel Rodrigues de melo & Não & $\operatorname{Sim}$ & $\operatorname{Sim}$ & $\operatorname{Sim}$ & $\operatorname{Sim}$ & Não \\
\hline 3 & EEEFM Dr. Hortêncio de S. Ribeiro & $\operatorname{Sim}$ & $\operatorname{Sim}$ & $\operatorname{Sim}$ & $\operatorname{Sim}$ & Não & Não \\
\hline 4 & EEEFM Dr. Elpídio de Almeida & $\operatorname{Sim}$ & $\operatorname{Sim}$ & $\operatorname{Sim}$ & $\operatorname{Sim}$ & Sim & Não \\
\hline 5 & EEEFM Raul Córdola & Não & Não & Não & Não & Não & Sim \\
\hline 6 & EEEFM Monte Carmelo & Não & Não & Não & Não & Não & Sim \\
\hline 7 & EEEFM João Lelys & Não & Não & Não & Não & Não & Sim \\
\hline
\end{tabular}

Fonte: A autora, a partir de dados disponibilizados pelo Coordenador do PDDE na $3^{\mathrm{a} G R E / P B}$

É comum cada uma das escolas trabalhar com mais de um programa, por exemplo, Pro-EMI e Cidadã Integrada ou Cidadã Integral e Cidadã Integrada. Como se observa, três outras escolas aderiram ao Novo Pro-EMI, enquanto as quatro que haviam aderido o substituíram por outros. O Pro-EMI foi substituído pelo Programa Escola Cidadã Integral do governo estadual, que resulta de parceria firmada com o Instituto de Corresponsabilidade pela Educação (ICE), que já atua em vários outros Estados, conforme o Quadro 3 seguir. 
Quadro 3 - Atuação do ICE no Brasil

\begin{tabular}{|c|c|c|c|c|c|}
\hline $\mathrm{N}^{\circ}$ & Regiões & $\begin{array}{c}\text { Fund. } \\
1\end{array}$ & $\begin{array}{c}\text { Fund. } \\
\text { II }\end{array}$ & $\begin{array}{c}\text { Ensino Médio } \\
\text { integral }\end{array}$ & $\begin{array}{c}\text { Ensino Médio integrado e } \\
\text { Profissional }\end{array}$ \\
\hline \multicolumn{6}{|c|}{ Nordeste } \\
\hline 01 & Paraíba & -- & -- & 23 & 6 \\
\hline 02 & Pernambuco & 2 & 16 & 338 & 35 \\
\hline 03 & Sergipe & -- & -- & 16 & -- \\
\hline 04 & $\begin{array}{l}\text { Rio Grande do } \\
\text { Norte }\end{array}$ & - & - & 15 & 4 \\
\hline 05 & Ceará & 3 & 19 & -- & 112 \\
\hline 06 & Piauí & -- & -- & 10 & -- \\
\hline 07 & Maranhão & -- & - & 11 & 7 \\
\hline \multicolumn{6}{|c|}{ Norte } \\
\hline 08 & Amapá & -- & -- & 8 & -- \\
\hline 09 & Acre & -- & -- & 7 & -- \\
\hline 10 & Tocantins & -- & -- & 12 & -- \\
\hline 11 & Rondônia & -- & -- & 10 & -- \\
\hline \multicolumn{6}{|c|}{ Centro-Oeste } \\
\hline 12 & Mato Grosso & -- & -- & 14 & -- \\
\hline 13 & $\begin{array}{l}\text { Mato Grosso do } \\
\text { Sul }\end{array}$ & -- & - & 12 & -- \\
\hline 14 & Goiás & -- & -- & 48 & -- \\
\hline \multicolumn{6}{|c|}{ Sudeste } \\
\hline 15 & São Paulo & -- & 182 & 186 & -- \\
\hline 16 & Rio de Janeiro & & 28 & -- & -- \\
\hline 17 & Espírito Santo & -- & 3 & 17 & -- \\
\hline
\end{tabular}

Fonte: A autora, a partir da dados disponíveis em ICE (2018b)

De acordo o Jornal do Comércio (2017), o ICE teve origem em 2004 no Recife/PE com a criação dos Centros de Ensino em tempo integral (Procentro) pela Secretaria de Educação do Estado, quando Marcos Magalhães, um engenheiro e ex-aluno ilustre do Colégio de Pernambucno, resolveu reunir empresários para restaurar o colégio que havia sido abandonado. O projeto se ampliou e após 13 anos, com a experiência bem sucedida com escolas em tempo integral, Pernambuco saiu da $22^{\mathrm{a}}$ para a $1^{\mathrm{a}}$ posição no IDEB e virou modelo para o País. Em 2016, o modelo foi adotado na Paraíba com os programas Escola Cidadã Integral e Escola Cidadã Integrada, em estágio de implementação em vários municípios.

A proposta de gestão administrativa e pedagógica das escolas e das redes de ensino ou o que o ICE denomina de Tecnologia de Gestão Educacional (TGE) está articulada ao projeto norteamericano da "Escola da Escolha". Nos documentos orientadores do projeto (ICE, 2018a, introdução p. 7), a TGE pode ser definida como

a arte de integrar tecnologias específicas e educar pessoas. No contexto da Escola da Escolha, educar pessoas significa criar um ambiente educacional onde todos, gestores e educadores, sintam-se estimulados a aprender e a pôr em prática seus conhecimentos a serviço do estudante e seu Projeto de Vida. O Modelo Pedagógico e a TGE são indissociáveis e constituem o organismo que torna possível transformar a visão e a missão da escola em efetiva e cotidiana ação.

A proposta é de educação integral e enfatiza o protagonismo estudantil e a avaliação contínua de todos os envolvidos de forma recíproca. Portanto, os profissionais são sistematicamente avaliados pelos pares e pelos estudantes. Esse protagonismo enfatiza a atuação dos estudantes na gestão da escola e de 
suas vidas, no âmbito da cidadania aproximando tais concepções das teorias tradicionais de currículo, que trabalham no sentido de ajustar os indivíduos às sociedades liberais, diferentemente das teorias críticas que orientam no sentido da transformação da sociedade e da utopia socialista.

O ICE faz parte de um esquema altamente complexo, conforme visualiza-se no Quadro 4.

\section{Quadro 4-O ICE e seus parceiros}

\begin{tabular}{|c|l|}
\hline PARCEIROS & \multicolumn{1}{c|}{ CARACTERÍSTICA E MISSÃO } \\
\hline ESTRATÉGICOS & $\begin{array}{l}\text { Instituto Natura: organização não governamental criada em 2010. Com o auxílio de } \\
\text { uma rede de parceiros, o instituto executa e apoia projetos voltados à melhoria da } \\
\text { Educação Básica na rede pública no Brasil e na América Latina, pautados na eficácia } \\
\text { da aprendizagem, na equidade de resultados e na coesão social. } \\
\text { Instituto Sonho Grande: organização não governamental que acredita na mudança } \\
\text { do país por meio da melhoria da Educação Básica, de forma mensurável e com } \\
\text { escala. }\end{array}$ \\
\hline TÉCNICOS & $\begin{array}{l}\text { Instituto Qualidade na Educação: entidade privada sem fins econômicos fundada } \\
\text { em S. Paulo em 1994 e mantida com o apoio de empresas privadas e parcerias com } \\
\text { governos estaduais e municipais. Sua missão é contribuir para a melhoria do } \\
\text { processo de ensino-aprendizagem nas escolas da rede pública, notadamente no } \\
\text { Ensino Fundamental, nas disciplinas de Língua Portuguesa, Matemática e Ciências. } \\
\text { STEM - Brasil: entidade privada sem fins econômicos, subsidiária do World Fund } \\
\text { for Education com sede em Nova York, fundada em 2002, que visa contribuir para } \\
\text { a melhoria da qualidade da educação pública na América Latina, notadamente no } \\
\text { ensino de Matemática, Ciências e Robótica. No Brasil atua em Escolas Públicas } \\
\text { através da formação dos professores das áreas de Física, Química, Biologia e } \\
\text { Matemática e a iniciação científica dos alunos através de práticas e vivências em } \\
\text { laboratórios. }\end{array}$ \\
\hline INVESTIDORES & $\begin{array}{l}\text { Instituto Natura- Instituto Sonho Grande- Espírito Santo em Ação-Itaú BBA-FIAT - } \\
\text { JEEP- Trevo- SEM }\end{array}$ \\
\hline INVIVADOS & Secretarias estaduais e municipais \\
PÚBLICOS & \\
\hline
\end{tabular}

Fonte: A autora, a partir de dados disponíveis em ICE (2018b).

Os investidores privados financiam o ICE e para isto firmam contratos com secretarias estaduais e municipais principalmente para obtenção de isenções e imunidades. As secretarias continuam financiando as escolas, que passam a receber assessoria administrativa e pedagógica. Ou seja, $\mathrm{O}$ financiamento se mantem público, porém a gestão torna-se privada. Do Quadro 5, destaca-se o STEM - Brasil que é um braço da World Fund for Education, uma instituição norteamericana com atuação expandida para a América Latina ${ }^{5}$. Esta instituição é adepta e vinculada à rede de Escola Charter da qual emerge o projeto da Escola da Escolha, que fundamenta o ICE. Holmes (2016) explica que a Escola charter é mantida com recursos públicos, mas cuja gestão é privada e teve origem na década de 1980, curiosamente pensada para ser uma escola liderada por professores e para acolher os alunos que fracassavam nas escolas tradicionais. Pensavam que poderiam contornar regras administrativas para poder experimentar diferentes abordagens de ensino com estudantes que enfrentam desafios maiores. Lamentavelmente, segundo Holmes, essa boa ideia virou uma indústria poderosa, que compete com as escolas públicas para atrair estudantes e recursos públicos preciosos.

No Brasil, estados tais como Paraíba, Sergipe, Ceará, Piauí, São Paulo e Rio de Janeiro adotaram variações desse modelo. Já em Goiás, o caminho tem sido a transferência da gestão das escolas para organizações sociais, com mudanças das condições de trabalho, como o fim do concurso público e o pagamento de bônus aos professores conforme o rendimento dos alunos - o que mantém o baixo nível salarial.

\footnotetext{
${ }^{5} \mathrm{Na}$ América Latina, o país pioneiro na transferência de escolas públicas para gestão privada foi o Chile durante a ditadura de Augusto Pinochet (1973-1990), em pleno processo de privatização de todos os serviços públicos.
} 
Os interesses que ficam por trás destes "partidos" (instituições) nem sempre são facilmente notáveis. Como assevera Borges (2016), a filantropia pode ser usada para vários fins: o honesto desejo por um mundo melhor, a "lavagem de consciência", o tráfico de influência e até a lavagem de dinheiro. Os benefícios mais evidentes e imediatos se dão por meio de isenções fiscais e imunidades tributárias educacionais concedidas pelos governo a essas fundações. Além disso, Borges (2016) defende que as grandes empresas têm interesse na formação de funcionários/trabalhadores para seus próprios quadros, o que pode ser atendido por meio da educação pública.

Na análise de Shiroma, Garcia e Santos (2011), os discursos que impregnam esse paradigma são tão contundentes que se comparam a discursos religiosos com alto poder de "converter almas". Partem da crítica bem fundamentada às falhas na gestão pública e aos indicadores vergonhosos à defesa dos princípios de mercado como base à gestão das políticas e dos processos de ensino e aprendizagem. Essa capacidade de "conversão" consiste em processo de hegemonização desse discurso, o que ocorre em torno do significante qualidade e da sua capacidade de articular diferentes demandas e sujeitos (empresários, políticos, pais, estudantes, profissionais, partidos, sindicatos, comunidades). Assumindo com Laclau, qualidade como significante vazio, Salvino (2014, p. 326) defende que

Para hegemonizar um novo sentido (um novo projeto, uma demanda particular), é necessário operar com a lógica da representação em ambientes e condições em que vários sentidos encontram-se sedimentados e legitimados. Para modifica-los, Laclau (2011) defende que os indivíduos do poder de representar operem com a lógica da desconstrução, quando os sentidos são postos sobre suspeita, problematizados e subvertidos alargando o campo da indecidibilidade e possibilitando as decisões políticas, que serão sempre contingenciais e provisórias.

Para essa desconstrução, a flutuação de sentidos é imprescindível, mas ela depende de elementos convincentes (concordância de profissionais, estudantes; estatísticas de $\mathrm{SAEB}^{6}$, IDEB ${ }^{7}$, PISA ${ }^{8}$, por exemplo) de que a oposição à governança (redes políticas) possui alternativa plausível, capaz de garantir melhores efeitos/resultados do que o projeto hegemônico. O jogo político que hegemoniza discursos e projetos educacionais, como outros, nunca se esgota, nunca se fecha em definitivo. Ao contrário, está sempre em deslocamento, em desconstrução, mas enquanto não se apresente alternativa potente/convincente ao que esta posto, as redes políticas continuarão avançando no sentido do que Ball (2014) nomeia de neoliberalismo roll-out ou de outro paradigma ainda desconhecido.

\section{CONSIDERAÇÕES FINAIS}

A política de parceirização público-privado em educação encontra-se bastante consolidada e com a perspectiva de continuar se fortalecendo, todavia, seus efeitos/resultados ainda são bastante imprecisos e questionáveis, uma vez que a educação se constitui em um rico e promissor mercado. Todavia, é necessário lembrar que as políticas não são o que idealizadores, legisladores, políticos, empresários propagam ou querem que elas sejam. Seus efeitos/resultados estão para além das vontades, dos discursos, dos projetos desses e outros sujeitos. Por vezes, as percepções destes ficam a depender dos discursos veiculados muito mais do que dos fatos, principalmente pelos lugares que ocuparem nas mídias digitais e televisivas, bem como no campo acadêmico/científico quando passam a proteger, silenciar, evidenciar determinados dados e informações em detrimento de outros.

O neoliberalismo é um sistema, uma realidade, que impregna a política de Estado e de governos e na sua versão "roll-out" configura-se a partir de redes políticas complexas, que extrapolam os limites do Estado-nação, mas também constituindo-se em práticas discursivas com intensa penetração na vida cotidiana para direcionar modos de pensar, de ser e de posicionar-se na sociedade. Ele se reproduz pelo

\footnotetext{
${ }^{6}$ Sistema de Avaliação da Educação Básica.

7 Índice de Desenvolvimento da Educação

${ }^{8}$ Programme for International Student Assessment
} 
domínio e regulação das relações cotidianas. Contudo, é imprescindível escapar da lógica reprodutivista de educação e de currículo, assumindo, que alunos, profissionais, comunidades escolares não são meros receptores e reprodutores de conhecimentos, informações, valores. São, antes de tudo, sujeitos que ressignificam, recriam, recontextualizam ideias, projetos, políticas (o instituído), portanto, politizam/repolitizam o currículo. O reprodutivismo imobiliza, não vislumbra e não encontra alternativas que, na maioria das vezes, encontram-se nos antagonismos, contradições e dinâmicas do próprio neoliberalismo.

O avanço da governança em rede não irá cessar, a tendência é de que a inserção ao mundo do trabalho se torne cada vez mais difícil, exigente e precária, por vezes, uma educação integral de qualidade, faz-se imprescindível. Seguindo as reflexões de Kohan (2009) acerca do ensino da Filosofia, defendo que, assim como se julga essencial reivindicar novas instituições e ou velhas instituições, deve-se postular que os processos de ensinar/aprender (Filosofia ou qualquer outra disciplina) não se reduzem às suas aparências institucionais, uma vez que excedem as instituições e devem possibilitar a análise da história e dos efeitos das próprias instituições. Sem dúvida, ainda que regulado, esses processos se manterão livres em alguma proporção, potencializando a força da pergunta, da problematização, da reflexão, do pensar, que são elementos-chave para mudanças sociais significativas.

\section{REFERÊNCIAS}

BALL, Stephen. Educação global S. A.: novas redes políticas e o imaginário neoliberal. Tradução de Janete Bridon. Ponta Grossa, PR: Editora da UEPG, 2014.

BALL, Stephen. Abordagem do ciclo de políticas: uma contribuição para a análise de políticas educacionais. Educação e Sociedade, Campinas, SP, v. 27, n. 94, p. 47-69, jan./abr. 2006. Disponível em: <http://www.cedes.unicamp.br>. Acesso em: 20 set. 2017.

BORGES, Helena. Conheça os bilionários convidados para "reformar" a educação brasileira de acordo com sua ideologia. 2016. In: The Intercept Brasil. Disponível em: https://theintercept.com/2016/11/04/conhecaos-bilionarios-convidados-para-reformar-a-educacao-brasileira-de-acordo-com-sua-ideologia/. Acesso em: 12 fev. 2018.

BRASIL. Ministério da Educação. Lei no 9.394, de 20 de dezembro de 1996. Brasília: MEC, 1996.

BRASIL. Casa Civil. Lei $n^{\circ}$ 9.608, de 18 de fevereiro de 1998. Brasília: Casa Civil, 2013.

INSTITUTO DE CORRESPONSABILIDADE PELA EDUCAÇÃO-ICE. Tecnologia de Gestão Educacional. Disponível em:

http://paraiba.pb.gov.br/pdfs/Caderno\%20de\%20Forma\%C3\%A7\%C3\%A30\%20Completo.pdf. Acesso em: 18 mar. 2018a.

BRASIL. Escola da Escolha. Disponível em: http://icebrasil.org.br/escola-da-escolha/. Acesso em: 18 mar. 2018b.

FUNDAÇÃO LEMANN. Encontro com 24 redes municipais de educação. Disponível em: https://www.fundacaolemann.org.br/noticias/encontro-com-24-redes-municipais-de-educacao. Acesso em: 20 mar. 2018.

GAUDÊNCIO, Frigotto. Os circuitos da história e o balança da educação na promeiroa década do século XXI. In: Revista Brasileira de Educação, v. 16 n. 46 jan./abr. 2011. Disponível em:

http://www.scielo.br/pdf/rbedu/v16n46/v16n46a13. Acesso em: 01 de dezembro 2016.

HOLMES, Dwight. Charter school: uma escola pública que caminha e fala como escola privada. Entrevista concedida à Nora Krawczyk em 31/05/2016. Disponível em:

http://www.cartaeducacao.com.br/entrevistas/charter-school-uma-escola-publica-que-caminha-e-falacomo-escola-privada/. Acesso em: 8 fev. 2018.

JORNAL DO COMÉRCIO. MEC leva escola Integral para todo o País. 2017. Disponível em: 
http://jconline.ne10.uol.com.br/canal/cidades/educacao/noticia/2017/07/19/mec-leva-escola-integral-paratodo-o-pais-296133.php. Acesso em: 10 mar. 2018.

LOPES, Alice Casimiro; Elizabeth Macedo. Teorias de currículo. São Paulo: Cortez, 2011.

OECD (2017), Education at a Glance 2017: OECD Indicators, OECD Publishing, Paris. http://dx.doi.org/10.1787/eag-2017-en.

SALVINO, Francisca Pereira; ROCHA, Vagda Gutemberg. Sentidos de "educação integral” nos meandros do Programa Mais Educação. In: Currículo sem Fronteira (online), v. 15, p. 684-714, set./2015. Disponível em: www.curriculosemfronteiras.org.br. Acesso em: 05/05/2015.

SALVINO, Francisca. Produção e circulação de conhecimento no Nordeste do Brasil. In: LOPES, Alice Casimiro; DE ALBA, Alicia (Orgs.). Diálogos curriculares entre Brasil e México. Rio de Janeiro: EdUERJ, 2014. P. 298-313.

SAVIANI, Dermeval. Política educacional brasileira: limites e perspectivas. In: Revista de Educação, PUCCampinas/SP, n. 24, p. 7-16, junho 2008.

SHIROMA, Eneida Oto; GARCIA Rosalba; CAMPOS, Roselane. Conversão das "almas" pela liturgia da palavra: uma análise do discurso do movimento Todos pela Educação. In: BALL, Stephen; MAINARDES, Jefferson (Orgs.). Políticas educacionais: questões e dilemas. São Paulo: Cortez, 2011.

TERRA. Google anuncia doação de R\$ 15,8 milhões para a Fundação Lemann. 2017. Disponível em: http://idgnow.com.br/internet/2017/03/22/google-anuncia-doacao-de-r-15-8-milhoes-para-a-fundacaolemann/. Cesso em: 15 mar. 2018.

THIESEN, Juares da Silva; DURLI, Zenilde. Territórios do currículo nas escolas públicas: o fenômeno da ocupação pela iniciativa privada. In: Espaço do Currículo, v.9, n.2, p. 288-302, Maio a Agosto de 2016. Disponível em: http://periodicos.ufpb.br/index.php/rec/article/viewFile/rec.vgi2.29274/16108. Acesso em: 20 fev. 2018. 